\title{
El espacio de la alcahueta: el marco urbano en La Celestina y La Lozana andaluza
}

\section{The procuress space: the urban framework in La Celestina and La Lozana andaluza}

\author{
JÉROMINE FRANCOIS \\ Université de Liège
}

Este artículo propone una comparación del tratamiento del espacio en La Celestina de Fernando de Rojas y en La Lozana andaluza de Francisco Delicado. A través de un estudio del marco urbano, de los recorridos, de la organización espacial en casas-calles-umbrales, y de la dicotomía entre lo público y lo privado, se evidencian el diálogo y la relación de rivalidad que Delicado inicia con su predecesor a partir de la topografía de su texto. Se verá que, aunque en ambos textos el personaje de la alcahueta se apodera de una configuración espacial urbana para cumplir con su faena, Celestina nivela los espacios destruyendo sus fronteras mientras que Lozana más bien tiende a crear nuevos espacios y a volverse una verdadera gestora del marco espacial. En este estudio se argumentará asimismo sobre las formas y funciones que La Lozana atribuye al espacio con el fin de posicionarse con respecto a su exitosa antepasada.

Palabras Clave: Celestina, Lozana, espacio, intertextualidad, rivalidad

This paper offers a comparison between spaciality as it is conceived in Fernando de Rojas's La Celestina and in Francisco Delicado's La Lozana andaluza. Through the study of the urban frame, the characters' trajectories, the spacial organization between houses-streets-tresholds, and the dichotomy between public and private, the dialogue and the rivalry that Delicado establishes with his predecesor as regards the topography of his text will be stressed. This paper will investigate how, in both texts, the go-between character seizes the urban spacial configuration to fulfill her duty. Celestina levels spaces by destroying theirs borders, whereas Lozana aims at creating new spaces and becoming a true agent of the spacial frame. This study will look into the forms and functions that La Lozana attributes to space in order to position itself in relation to its famous forerunner.

KEY wORDs: Celestina, Lozana, space, intertextuality, rivalry

$\mathrm{P}$ ara llevar a cabo su trabajo de alcahuetería, es decir, de mediación amorosa, la Celestina de Rojas realiza una serie de otras mediaciones a nivel social, sobrenatural y espacial. En efecto, Celestina representa sin duda el personaje más móvil de la Tragicomedia y esta característica le permite aprovecharse de la configuración de la ciudad que le sirve de escenario. Ahora bien, este singular tratamiento espacial bien podría dejar sus huellas en parte de la descendencia literaria de La Celestina. 
La Lozana andaluza de Francisco Delicado, por ejemplo, anuncia su competencia con La Celestina desde su título, en el que advierte que El cual retrato demuestra lo que en Roma pasaba, y contiene munchas más cosas que La Celestina. ${ }^{1}$ Esta confrontación con la obra de Rojas, a la que se invita de entrada, se afianza a lo largo de los mamotretos de La Lozana, en los que se multiplican las menciones directas y ecos más alusivos al personaje de la Tragicomedia. En la mayoría de los casos, Celestina funciona como el término de comparación por antonomasia que utilizan los personajes para exaltar la fama y los dotes de la protagonista delicadiana. ${ }^{2} \mathrm{Al}$ observar a Lozana en la calle, uno de los personajes comenta, por ejemplo: "Diré yo como de la otra: que las piedras la conocién” (mam. XXIV, 119) y evoca así una réplica con la que Pármeno califica a Celestina en el acto primero. Más adelante, para resaltar la astucia de la alcahueta que le ha concertado una cita con la hermosa señora Angélica, un caballero exclama: "Monseñor, ésta es cárcel de Amor; aquí idolatró Calisto, aquí no se estima Melibea, aquí poco vale Celestina” (mam. XXXVI, 189). Lozana incluso posee un ejemplar de la Tragicomedia por la que tiene curiosidad y cuya lectura encarga a uno de sus clientes: "Lozana: Mi señor [...] quiero que me leáis, vos que tenéis gracia, las coplas de Fajardo y la comedia Tinalaria y a Celestina, que huelgo de oír leer estas cosas muncho./ Silvano: ¿Tiénela Vuestra Merced en casa?/ Lozana: Señor, velda aquí, mas no me la leen a mi modo, como haréis vos" (mam. XLVII, 236).

Desde el hallazgo de La Lozana en el siglo XIX, varios estudiosos examinaron las relaciones entre las obras de Rojas y Delicado. Según Nicasio Salvador Miguel ("Huellas de La Celestina", 457), La Lozana constituye una verdadera emulación de La Celestina. La peculiaridad del texto de Delicado, lo que la sitúa, en palabras de Jacques Joset, "fuera de órbita" ("El otro humanismo”, 357) en la celestinesca, es que rechaza la etiqueta de continuación de La Celestina, a diferencia de lo que harán unos años después Feliciano de Silva con su Segunda Celestina o Resurrección de Celestina (1534) o Gaspar Gómez de Toledo con una Tercera parte de la Tragicomedia de Celestina (1536).

1 Joset (“...y contiene”, 148) advierte que éste era ante todo un título publicitario dirigido a un público hispanoitaliano, ya que la Tragicomedia de Calisto y Melibea empezó a designarse como La Celestina a partir de 1519, año en el que se reimprimió con este título la versión italiana de Alfonso Ordóñez.

2 Nótese que esta relación de rivalidad entre Lozana y Celestina integra el sistema de competencia general que configura las relaciones entre los personajes lozanescos: tanto las cortesanas como los clientes masculinos de Lozana porfían con el fin de conseguir mejores cosméticos, más fama o rameras más guapas que los demás.

Medievalia 48, 2016, pp. 107-129 
Unos investigadores analizaron distintos aspectos de esta relación de rivalidad y pusieron de manifiesto sus implicaciones en cuanto a la originalidad textual del Retrato delicadiano. Han sido examinados, entre otros elementos, el parentesco formal (tanto genérico como estilístico) entre las dos obras, las citas y menciones de la Tragicomedia que aparecen en La Lozana así como los procesos de construcción de los personajes celestinescos heredados por Delicado. Jacques Joset (“...y contiene”) ha señalado, por su parte, otros niveles de competencia entre ambos textos al explicar cómo el Retrato plasma una rivalidad literaria, regional y lingüística entre el bachiller salmantino y el clérigo cordobés. El filólogo belga ha demostrado además que la intertextualidad clásica de la que hace alarde La Lozana, especialmente a través de su utilización del Asno de oro, participa también en dicha rivalidad.

El presente trabajo propone por su parte mostrar que el tratamiento literario del espacio constituye un aspecto suplementario y significativo de la competencia entre La Lozana y su antecesora. Más concretamente, aunque en ambos casos el personaje de la alcahueta se apodera de una configuración espacial urbana para cumplir con su faena, veremos que Celestina nivela los espacios destruyendo sus fronteras mientras que Lozana más bien tiende a crear nuevos espacios y a volverse una verdadera gestora del marco espacial. En este estudio, quisiera por consiguiente argumentar sobre las formas y funciones que La Lozana atribuye al espacio con el fin de posicionarse con respecto a su exitosa antepasada.

\section{GÉNESIS DE LA PROTAGONISTA}

A diferencia de La Celestina en cuya escena inicial sólo intervienen los amantes, La Lozana andaluza se centra de entrada en su personaje epónimo y más concretamente en sus andanzas espaciales. Los cuatro primeros mamotretos del Retrato conforman en efecto lo que la crítica suele llamar la "prehistoria" de Lozana y cuentan con una mezcla de narración y diálogos la juventud de la protagonista. Tal juventud es marcada por varios viajes que constituyen una verdadera formación sensual itinerante para Lozana:

Muerto su padre, fue necesario que acompañase a su madre fuera de su natural, y ésta fue la causa que supo y vido munchas ciudades, villas y lugares de

3 Véanse, entre otros, los trabajos de Botta (“Itinerarios urbanos”) y Salvador Miguel ("Huellas de La Celestina").

Medievalia 48, 2016, pp. 107-129 
España, que agora se le recuerdan de casi el todo, y tinié tanto intelecto que casi escusaba a su madre procurador para sus negocios. Siempre que su madre la mandaba ir o venir, era presta, y como pleiteaba su madre, ella fue en Granada mirada y tenida por solicitadora perfecta e prenosticada futura. Acabado el pleito, $[\ldots]$ acordaron de morar en Jerez y pasar por Carmona. Aquí la madre quiso mostrarle tejer, el cual oficio no se le dio ansí como el ordir y tramar, que le quedaron tanto en la cabeza, que no se lo han podido olvidar (mam. I, 13).

En esta primera etapa de su vida, los viajes por España permiten que Lozana desarrolle los dotes que la harán famosa cuando se instale en Roma: por una parte, su engañosa capacidad de adivinación; por otra parte, sus talentos sensuales, revelados por el doble sentido sexual que el texto asocia constantemente con los vocablos del campo semántico del tejer, hilar y coser. Después de la muerte de su madre, Lozana pasa brevemente bajo la tutela de su tía antes de convertirse en trotamundos por seguir a su amante, el mercader Diomedes que le advierte:

Yo me tengo de disponer a servir y obedecer a mi padre, el cual manda que vaya en Levante, y andaré toda la Berbería, y principalmente donde tenemos trato, que me será fuerza de demorar y no tornar tan presto como yo querría, porque solamente en estas ciudades que agora oirés tengo de estar años, y no meses, como será en Alexandría, en Damasco, en Damiata, en Barut, en parte de la Soria, en Chiple, en el Caire y en el Xío, en Constantinopoli, en Corintio, en Tesalia, en Boecia, en Candia, a Venecia y Flandes, y en otras partes que vos, mi señora, veréis si queréis tenerme compañía (mam. IV, 21).

Según Costa Fontes ("The Art of Sailing”), aquí también es posible interpretar en doble sentido los movimientos espaciales de Lozana, ya que sus viajes por el Levante con un mercader bien podrían representar alegóricamente el comercio del cuerpo de Lozana, o sea el inicio de su prostitución en el que "'sailing' constitutes a euphemism for intercourse”.

La historia de la formación lozanesca se asocia directamente con el viaje, pero estos primeros desplazamientos revelan siempre relaciones de dependencia: en estos primeros mamotretos, Lozana no conecta lugares y ni siquiera controla sus propios movimientos, sino que se deja llevar por otros personajes que tienen autoridad sobre ella: su madre, su tía y su rufián-marido, a quien declara: "seré siempre vuestra más que mía" (mam. III, 19) y "yo iré de muy buena voluntad donde vos, mi señor, me mandáredes" (mam. IV, 22).

Lozana valora sus recorridos como una fuente de sabiduría y de experiencias que condiciona su desarrollo posterior. Así declara Rampín: "Señores, 
dice [Lozana] que no tiene tierra, que ha sido criada por tierras ajenas" (mam. XIX, 96). Más lejos, la propia Lozana afirma: "Yo he andado en mi juventud por Levante, só estada en Nigroponte, y he visto y oído munchas cosas, y entonces notaba, y agora saco de lo que entonces guardé" (mam. XLVI, 228). Sus viajes constituyen la verdadera génesis de la protagonista y sobre todo la matriz de la filosofía experimental que ella preconiza: "más sabe quien muncho anda que quien muncho vive, porque quien muncho vive cada día oye cosas nuevas, y quien muncho anda, vee lo que ha de oír" (mam. L, 247).

$\mathrm{Al}$ contrario de Celestina, cuya génesis se reduce a unos recuerdos de su formación con Claudina, el personaje de Lozana se retrata de entrada como una figura formada por la deambulación. ${ }^{4}$ Aunque la alcahueta de Rojas también se presenta como una maestra en el arte del trotar, la tercera de Delicado se caracteriza además por una fuerte conciencia de esta capacidad y por una clara voluntad de apoderarse del recorrido espacial para emanciparse. Lozana transforma, en efecto, la deambulación, que anteriormente reflejaba sus relaciones de dependencia, en instrumento de autocontrol e independencia. Imperiale interpreta también los primeros mamotretos de La Lozana como la historia de una emancipación a la vez geográfica y psicológica. Con su llegada a Roma, destino que elige de forma autónoma, Lozana empieza a controlar sus movimientos: "a medida que sigue creciendo y después de vivir en sus viajes marítimos un sinnúmero de vicisitudes, se define en su identidad femenina, y, además, se emancipa definitivamente de la tutela homocéntrica” ("Itinerario peripatético", 99).

\section{PARALELISMOS ESPACIALES}

\section{Un marco urbano contemporáneo}

Tanto los diálogos de la Tragicomedia como los de La Lozana se ubican en un marco urbano, entorno que se desarrolla en la Castilla de finales del siglo XV y principios del XVI, dada la concentración urbana de la población a la que llevaron el crecimiento demográfico y el auge económico de esta parte de España en aquel entonces. Es este nuevo contexto de transición hacia la vida urbana que tipifican Rojas y Delicado en sus textos. En La Celestina,

4 De ahí que no tienen por qué sorprendernos el número de secuelas que inspiró La Celestina con el fin de subsanar los huecos. Véase por ejemplo la moderna obra de José Martín Recuerda titulada Las conversiones (1981).

Medievalia 48, 2016, pp. 107-129 
el funcionamiento de la ciudad se hace omnipresente a través de las distintas profesiones, esencialmente urbanas, que ejercen los personajes, la presencia de un reloj público o los ejemplos, proporcionados por los personajes, de una mentalidad burguesa pre-capitalista sobre todo preocupada por la nueva economía monetaria que se está instalando. La Celestina representa así, según José Antonio Maravall ("Afán de lucro"), un producto cabal de la cultura urbana. Patrizia Botta señala los parentescos ambientales entre los textos de Rojas y de Delicado aunque, según ella, el inframundo predomina en La Lozana:

En cuanto a la ambientación, es natural que el escenario de La Lozana sea el mismo que el de La Celestina: la ciudad, las calles, las plazas, el marco urbano no ya de casas patricias de Calistos y Melibeas sino de barrios de malvivientes y marginados, del mundo del hampa que lucha por el comer del día a día a expensas de una Roma curial y rica, la del Papado que asegura mercado y supervivencia a las prostitutas ("Itinerarios urbanos", 1).

No obstante, el tratamiento del espacio urbano difiere notablemente entre las dos obras: a la ciudad castellana indefinida en la que se desenvuelve Celestina se opone la Roma sumamente detallada de Lozana. Como bien es sabido, varios críticos han intentado identificar el referente real de la ciudad anónima en la que se desarrolla La Celestina. Salamanca, Toledo, Talavera de la Reina o Sevilla han sido propuestas como candidatas mientras que Stephen Gilman (La Celestina: arte y estructura) y María Rosa Lida de Malkiel (Two Spanish Masterpieces) por su parte preferían considerar la ubicación de $\mathrm{La}$ Celestina como una ciudad imaginaria, síntesis indudable de distintas urbes castellanas que Rojas debía conocer. El lector se entera del escenario urbano del texto cuando Sempronio, criado de Calisto, alaba los méritos de Celestina a quien describe como una alcahueta que tiene "autoridad en esta ciudad" (auto I, 47). ${ }^{5}$

Ahora bien, el espacio urbano en el que se instala Lozana con el fin de salir adelante no es otro que la ciudad eterna. Vemos aquí una primera diferencia clara con el modelo rojano: Delicado no sitúa a su protagonista en un marco castellano, sino que la ubica en un escenario italiano bien conocido por el clérigo cordobés. ${ }^{6}$ La insistencia en este marco romano es patente a lo largo

5 Como señalan los editores, el término ciudad se refería en "un determinado tipo de población, de considerable extensión y con un estatuto jurídico preeminente” (47, n. 23).

6 Para un pormenorizado estado de la cuestión sobre las circunstancias vitales de Delicado, véase la introducción de Folke Gernert (Delicado, La Lozana, 371-376). Evidentemente, 
de La Lozana y empieza desde el mismo título que presenta la obra como un fiel testimonio de la vida romana por ser "compuesto en Roma” y por "dem[ostrar] lo que en Roma pasaba”. A partir de un análisis del prólogo del Retrato, en el que se contrastan las andanzas romanas de Lozana y "el arte de aquella mujer que fue en Salamanca en tiempo de Celestino segundo" (5) —alusión velada a la Celestina de Rojas-, Jacques Joset señala que:

se instaura una tensión topológica entre Roma (esta alma ciudad), teatro de las hazañas de Lozana, y la Salamanca de Celestina, que volverá a aparecer de trecho en trecho en la obra de Francisco Delicado. El sentido de la oposición es clarísimo: la Roma de Lozana supera con creces la Salamanca de Celestina en libertad de costumbres y vicios de toda clase (“...y contiene”, 149).

Roma se describe en efecto en varios mamotretos como la "ciudad meretrice" (mam. XXIV, 129) por antonomasia, "capa de pecadores" (mam. XXIV, 130), en la que pululan celestinas de distintas naciones, ${ }^{7}$ y cuyo Tíber es aun más carnicero que el río de Salamanca, como advierte Lozana: "este Tíber es carnicero como Tormes, y paréceme que tiene éste más razón que no el otro" (mam. LIII, 259). De este modo, Roma se describe no como centro de la cristiandad sino como ciudad de los amores carnales y ciudad de corrupción: "la ciudad atrae como imán a las prostitutas de todo el mundo" (Wardropper, "La novela como retrato", 485). Estas descripciones algo hiperbólicas contribuyen por tanto a presentar la ciudad romana como el marco más adecuado para el ejercicio de la tercería y el comercio del amor. De hecho, las repetidas alusiones al famoso palíndromo Roma-Amor que hace Lozana participan también en esta presentación. ${ }^{8}$ Todo parece indicar que la cordobesa eligió así su escenario de una forma muy acertada.

Esta simbiosis entre el personaje delicadiano y su entorno espacial irá afianzándose a medida que progresa el texto, hasta que el retrato de Lozana se confunda con el retrato de Roma. Bien lo ha recalcado Hernández Ortiz:

también conviene interpretar la elección del espacio romano en el marco del humanismo sui generis de Francisco Delicado. Sobre esto véase Joset, "El otro humanismo".

7 Lozana le pregunta a uno de sus clientes: "¿Qué quiere decir que vienen tantas a ser putas a Roma?", a lo cual contesta el Valijero: "Vienen al sabor y al olor, de Alemaña son traídas, y de Francia son venidas. Las dueñas de España vienen en romeaje, y de Italia vienen con carruaje" (mam. XXI, 108).

8 Véanse por ejemplo el mamotreto LXVI "es bueno huir romano por Roma que, voltadas las letras, dice Amor, y entendamos en dejar lo que nos ha de dejar" (322), o la Epístola de Lozana "que voltando las letras, dice Roma, amor" (348).

Medievalia 48, 2016, pp. 107-129 
"Si Lozana es el eje central de la obra, Roma es la circunstancia poderosa cuyos valores se entrecruzan, muchas veces, con los de la heroína y cuya vida y costumbres son parte fundamental de la novela” (La génesis artística, 93). Cuando un maestresala le pregunta a la joven andaluza qué opinión tiene de Roma, le contesta Lozana: "Señor, diré como forastera: 'La tierra que me sé, por madre me la he'. Cierto es que, hasta que vea, ¿por qué no le tomaré amor?/ Maestresala: Señora, vos sois tal y haréis tales obras, que no por hija mas por madre quedaréis de esta tierra" (mam. XIX, 92).

En este contexto tan propicio, Lozana decide conscientemente aprovecharse del espacio romano como lugar de aprendizaje para lograr su independencia, objetivo que persigue desde su separación algo brutal con Diomedes: “miraba también cómo hacían aquéllas que entonces eran en la ciudad, y notaba lo que le parecía a ella que le había de aprovechar, para ser siempre libre y no sujeta a ninguno" (mam. V, 26). Otra vez, la deambulación espacial le servirá como manantial de saberes y experiencias. El paseo por Roma con su futuro acólito Rampín se asemeja así más a una misión de reconocimiento del terreno que a una sencilla visita: "Pues hace una cosa, mi hijo, que por do fuéremos que me digáis cada cosa qué es y cómo se llaman las calles” (mam. XII, 46). Rampín la guía por la ciudad a través de un largo recorrido en el que Lozana muestra una constante preocupación por la ubicación de los distintos barrios, busca establecer redes de contactos y pide informaciones sobre las profesiones, creencias, los caracteres y orígenes de cada sector de la población. Su joven cicerón le presenta entonces a las cortesanas y los obispos con los que se cruzan. En sus explicaciones, Rampín no duda en enfatizar los engaños y las estrategias de sobrevivencia de cada uno. A pesar del carácter más bien utilitarista del primer recorrido romano de Lozana, cabe señalar que el paseo tampoco carece de valor histórico, ya que Rampín también enseña a su futura ama y amante la Roma clásica:

Por aquí, por Plaza Redonda, y verés el templo de Panteón, y la sepultura de Lucrecia Romana, y el aguja de piedra que tiene la ceniza de Rómulo y Rémulo, y la Colona labrada, cosa maravillosa, y veréis Setenzonéis (mam. XV, 68-69).

Nótese que este carácter arqueológico del humanismo de Delicado (Joset, "El otro humanismo", 364) también se refleja en el mamotreto XLVII, dedicado a la descripción de la Peña de Martos, patria chica del autor de La Lozana (véase Bubnova, "Delicado en la Peña”). Bubnova se cuestionó acerca de la "validez de las referencias históricas, geográficas y arqueológicas de Delicado" ("Delicado en la Peña”, 71), subrayando el "escaso interés por las 
antigüedades romanas". Según la estudiosa, "el repentino interés por la epigrafía, los monumentos y las leyendas de [la Peña de] Martos” que demuestra nuestro autor es algo sorprendente frente a la actitud "antirrenacentista" del mismo autor "en lo que al aprecio de los monumentos de la Antigüedad clásica se refiere" (Bubnova, "Delicado en la Peña”, 71). No obstante, como acabamos de ver, el recorrido por Roma del mamotreto XII y del mamotreto XV en el que Rampín guía a Lozana desde el Coliseo hasta el Panteón hace alarde de la representación, en el Retrato, de la Antigüedad monumental.

Las repetidas menciones de topónimos romanos, y más generalmente el tratamiento del espacio urbano en La Lozana han sido interpretados con frecuencia como "uno de los principales elementos de la ficción en que se percibe la vocación realista de Delicado" (Gernert, en Delicado, La Lozana, 455). ${ }^{9}$ Esta lectura realista, eje de análisis predominante desde el descubrimiento de La Lozana, es por ejemplo la lectura que preconizan Wardropper ("La novela como retrato") o Hernández Ortiz (La génesis artística), en la célebre monografía que dedica a la obra de Delicado. Según este último crítico, gran parte de la crítica social de La Lozana se arraiga en la descripción realista de los espacios del hampa romana: "Así, de la representación verídica del mundo amoral de Roma, Delicado saca el fin didáctico" (Montserrat Villagrá, La Lozana andaluza en el siglo de los humanistas, 434).

\section{Recorridos espaciales}

Según Gilman, María Rosa Lida de Malkiel y otros destacados especialistas de La Celestina, una de las características más llamativas de la obra de Rojas es que el lugar no constituye una geografía descrita de antemano y en la cual la acción viene a deslizarse, sino que más bien representa un recorrido espacial que viene creándose al hilo de los diálogos, a partir de las necesidades de los personajes. No hay descripciones gratuitas de los espacios, ni siquiera acotaciones que anuncien los cambios de decorados o los desplazamientos de los personajes. Cada espacio y cada transición de un espacio a otro tiene que ser inferido a partir de los mismos diálogos, y los personajes sólo cambian de lugar o se refieren a las características de un lugar en la medida en que les ayuda a lograr sus objetivos de lucro. Fuerza es constatar que tal construcción dialogística y tal utilitarismo del recorrido espacial vuelven a aparecer en el texto de Delicado.

9 La toponimia de La Lozana ha sido estudiada por Botta (“Onomástica”). 


\section{Repartición espacial}

En La Celestina, la configuración de la ciudad en distintos barrios no sólo permite repartir a los personajes a nivel espacial, sino que también organiza y define las relaciones humanas y los vínculos sociales. En esta tragicomedia, el lugar, pues, sólo aparece y se define en función de los personajes que lo pueblan a la vez que contribuye a definir a sus habitantes. Puesto que $L a$ Celestina representa ante todo una historia de idas y vueltas de los personajes, la ciudad se organiza en tres tipos de lugares distintos: las casas, las calles y los umbrales. Ahora bien, conviene preguntarse si tal repartición guía también la estructura espacial de La Lozana y, en caso afirmativo, si se mantienen las funciones otorgadas a cada uno de estos lugares en La Celestina.

\section{3.1. Casas y repartición social}

Las casas de La Celestina suelen caracterizar de forma metonímica a sus habitantes. Por una parte, la ubicación de las casas es un buen indicador del estatuto que ocupan sus habitantes en la sociedad. Por otra parte, las habitaciones de la morada en las que se centra el texto revelan las actividades principales y la personalidad de los personajes.

Es evidentemente el caso de la casa de Celestina que Pármeno describe a Calisto: la alcahueta tiene "al cabo de la ciudad, allá cerca de las tenerías, en la cuesta del río, una casa apartada, medio caída, poco compuesta y menos abastada" (auto I, 54). En esta descripción, es evidente la marginalidad espacial de la casa, en la periferia: cerca de las malolientes tenerías, esta casa "medio caída" y poco abastada refleja la miseria económica que padece Celestina. El lugar en el que vive Calisto es también sintomático de su situación económica: su morada, que se beneficia de varias salas, patios, caballerizas y del servicio de criados, hace alarde de un tren de vida acomodado. Es, sobre todo, la recámara de Calisto que constituye, en esta casa, el lugar que éste habita con más frecuencia: el aislamiento del personaje, que se encierra en su cuarto, se debe aquí no sólo a una tendencia a la holgazanería típica de su condición de caballero, sino también a sus emociones. En circunstancias alegres o adversas, Calisto tiende a concentrarse sobre sus propios pensamientos y a olvidarse del funcionamiento de su casa y de sus deberes como amo.

La casa de Pleberio, por su parte, constituye una morada noble bastante típica. Protegida por altos muros, adornada con un jardín cerrado y dotada de una torre, este espacio hace hincapié en las estrategias previstas por el patriarca con el fin de aislar a su hija y hacer de ella una "encerrada doncella" (auto X, 219). Estas características transforman la casa de Pleberio en un símbolo de 
poder, riqueza y de inaccesibilidad envidiado por los demás personajes, como señala Celestina cuando afirma "yo soy querido por mi persona; el rico por su hacienda" (auto IV, 120).

Sin embargo, cuando Calisto supera estos obstáculos, el jardín de la casa constituirá a su turno un verdadero locus amoenus para los amantes, y Calisto lo describe como "aquel paraíso dulce, en aquel alegre vergel entre aquellas suaves plantas y fresca verdura" (auto XIV, 281). El marco espacial se adecua otra vez al talante y a las actividades de los personajes. Como se ve, cada uno está en el sitio previsto al principio de La Celestina. La repartición espacial refleja la repartición social, y cada casa representa un microcosmo social percibido como un refugio por sus habitantes.

En La Lozana andaluza, la casa constituye también una fuente de inquietud mayor para la protagonista. Si Pleberio edifica una casa como baluarte de la honra familiar, Lozana, por su parte, se preocupa por una consideración social que ya no se expresa en términos de linaje, sangre o castidad (honra), sino en meros términos de renombre y de opiniones ajenas favorables (fama). La ramera y luego alcahueta cordobesa pretende sobre todo asentar su fama a partir de su casa. Por eso, y al contrario de su modelo rojano que vive en la periferia en una casa poca abastecida, Lozana se instala en el barrio central de la Aduana (mam. XVI), en una casa que "tiene por sí" (mam. XXIV, 120) y que aprovisiona constantemente. ${ }^{10}$

Es la misma búsqueda constante de una fama renovada que lleva a que Lozana se mude más adelante, lo cual no deja de asombrar a sus clientes:

Escudero: ¿Y por qué quiere Vuestra Merced dejar su vecindad?

Lozana: Señor, quien se muda, Dios lo ayuda.

Escudero: No se enmohecerán vuestras baratijas, ni vuestras palomas fetarán.

Lozana: No me curo, que no soy yo la primera. Las putas cada tres meses se mudan por parecer fruta nueva.

Escudero: Verdad es, mas las favoridas no se mudan.

Lozana: Pues yo no só favorida, y quiero buscar favor (mam. XXXIV, 173).

Cuando la fama de Lozana es tal que no puede salir a la calle sin ser reconocida y acosada, los proyectos de desarrollo de su negocio se enfocan aún más en su casa:

10 Los demás personajes comentan con admiración esta capacidad que tiene Lozana para abastar su casa. Véase por ejemplo la réplica del compañero del autor, en el mamotreto XXIV (120-121).

Medievalia 48, 2016, pp. 107-129 
Deseo tenía de venir a mi casa, que como dicen, "mi casa y mi hogar, cien ducados val”. Ya no quiero andar tras el rabo de putas. Hasta agora no he perdido nada; de aquí en adelante quiero que ellas me busquen. No quiero que de mí se diga puta de todo trance, alcatara a la fin. [...] que mi casa será colmena; y también, si yo asiento en mi casa, no me faltarán munchos que yo tengo ya domados, y mitirillo por encarnazar (mam. XLI, 210-211; cursivas mías).

Según Olalla, las "constantes alusiones al valor de su oficio y a la importancia de tener una casa propia, bien acomodada y bien provista" ("Tú no has venido", 569), representan valores propios del código moral burgués que se está desarrollando en la época de Delicado. No obstante, es posible interpretar de otra forma este pasaje, en el que, a juicio de Lozana, la concentración de todas sus actividades en su casa-mancebía representaría una etapa suplementaria en su carrera prostibularia. A la telaraña celestinesca, en la que la trotaconventos se desplaza constantemente de un cliente a otro, Lozana opone por tanto otro funcionamiento, que para ella significa a la vez más autonomía y más reconocimiento: el de la colmena. ${ }^{11}$ En efecto, a partir del mamotreto XLI, las visitas de Lozana en casas ajenas se reducen de forma notable y más bien son los demás personajes quienes gravitan alrededor de la alcahueta, dueña y reina de una casa a la que todos acuden.

La obsesión de Lozana por la fama de la que su casa es depositaria sigue siendo un verdadero leitmotiv de los mamotretos siguientes. Así, Lozana invita a comer al vagabundo Sagüeso a condición de que éste acepte pregonar la superioridad de la alcahueta:

Sagüeso: ¡Por vida del gran maestro de Rodas, que me convidéis a comer sólo por entrar debajo de vuestra bandera!

Lozana: ¿Por qué no? Entrá en vuestra casa y mía, y de todos los buenos, que más ventura tenéis que seso; pero entrá cantando:

¿Quién mayor que la Celidonia?

Lozana y Rampín en Roma (mam. LII, 255).

11 La única mención de la araña en la Tragicomedia no se refiere a Celestina, sino que ésta la dirige a Melibea (auto IV: 130), pero, como anotan Blay y Severin, "this would seem to be displacement by Celestina, a better candidate for this image" (Animals in Celestina, 16); véase también Weinberg ("Aspects...", 151-153). Hay otras referencias a la "red", pero se relacionan más directamente con la caza y la pesca (Deyermond, "Hilado-cordón-cadena”, 6). Nótese además que la vieja alcahueta entra en casa de Melibea bajo el pretexto de vender hilado.

Medievalia 48, 2016, pp. 107-129 
Un destacado punto común entre la casa de Lozana y la casa de Celestina consiste en su función de foro: tanto la vieja alcahueta como su émula cordobesa crean con su casa un espacio de palabra libre para todos y ponen sobre el tapete algunos temas candentes. La primera, en la famosa escena del banquete del noveno auto, en la que Areúsa ataca sin contención a Melibea y a las relaciones entre amas y criadas. La segunda, en varios mamotretos en los que Lozana comenta con sus clientes el problema de la marginalidad social y de la falta de reconocimiento que sufren las rameras. En este marco, la andaluza incluso propone la creación de un nuevo espacio que compense esta falta de reconocimiento: una "taberna meritoria" (mam. XLIV, 223), que simbolice el agradecimiento público hacia el penoso trabajo de interés común que efectúan las rameras. Es de notar que la actitud comprometida de la andaluza, que aquí hace alarde de cierto deseo de renovación social, se acerca más a la diatriba de Areúsa que a las críticas formuladas por Celestina a lo largo de la Tragicomedia.

A diferencia del espacio de La Celestina, el marco urbano de La Lozana no refleja tanto los estatutos sociales de sus habitantes. En efecto, las jerarquizaciones sociales parecen caducas, dada la peculiaridad del marco romano: "Pues por eso es libre Roma, que cada uno hace lo que se le antoja, agora sea bueno o malo. [...] ¿Pensáis vos que se dice en balde, por Roma, Babilón, sino por la muncha confusión que causa la libertad?” (mam. XXIV, 129). Aquí se afianza aún más la identificación de la protagonista delicadiana con su espacio, pues tanto Roma como Lozana se describen como meretrices sensuales y libres. Para Lozana poco valen las distinciones de linaje o de estatuto social, ya que se comporta igual con cualquier interlocutor y trata a todos de la misma manera, con este lenguaje teñido a la vez de cultismos, palabras soeces y chistes verdes. No obstante, la forma en la que la andaluza organiza su negocio a nivel espacial sí depende en buena medida del nivel económico de sus clientes: Lozana sólo se desplaza al domicilio de sus clientes si se trata de cortesanas de altos vuelos o de ricos señores. ${ }^{12}$

Cuando no se desplaza, la alcahueta delicadiana recibe a sus clientes en su propia casa, que funciona a la vez como mancebía, consultorio médico y centro de belleza. A modo de ejemplos, se pueden mencionar los mamotretos XIX — con el desfile de clientes masculinos a los que tiene que atender Lozana - o el LIII — en el que Lozana concierta una relación carnal entre Sagüeso y Divicia en una escena que no deja de recordar el encuentro que

12 Véanse por ejemplo los mamotretos XXV, XXVIII, XXXI, XXXV, XXXVII. 
orquesta Celestina entre Areúsa y Pármeno. Además de esta variedad de papeles, la casa de Lozana también funciona de cierto modo como un lugar de enseñanza en el que la alcahueta comparte sus saberes en materia de afeites, su conocimiento del ser humano y su arte del engaño con algunos clientes que se vuelven discípulos suyos (mam. LV, LXIII o LXV). Lozana asume, por ejemplo, una postura de profesora cuando emprende la educación sexual de una boba y así afirma: "habéis de saber que me place [la pregunta de la boba], porque el dicípulo que no duda ni pregunta no sabrá jamás nada” (mam. LXIII, 311).

De forma general, son los clientes de Lozana quienes llegan a ella, sin que tenga que buscarlos. Uno de éstos comenta, por ejemplo: "Así que vamos por aquí, veamos qué hace, que yo también ando tras ella por mis pecados, 120 que cada día me promete y jamás me atiende" (XXX, 154). Los trayectos de Lozana reflejan por tanto la repartición y organización precisa de sus actividades, que estructura según el poder económico de sus clientes. Al contrario, la mayor parte del trabajo de Celestina, tal y como se representa en la Tragicomedia, es ambulante: la vieja se apresura constantemente, viene "haldeando" (auto IV, 113), y se queja constantemente de sus faldas que le estorban el paso. ${ }^{13} \mathrm{El}$ personaje de Lozana se representa como una verdadera mujer de negocios, más organizada y más dueña de sus desplazamientos que su modelo rojano. ${ }^{14}$ Es de notar que esta caracterización del personaje lozanesco también revela una lectura pormenorizada de Rojas por Delicado: al fin y al cabo, esta andaluza en la cumbre de su arte bien podría ejemplificar los años de gloria de Celestina que se describen en el auto IX de la Tragicomedia.

\subsection{Calles}

En La Celestina, las calles cumplen su función habitual como lugares de tránsito. En la mayor parte del texto, sólo las bajas clases sociales se desplazan por esta red, de mala fama por considerarse peligrosa. Los personajes con frecuencia temen ser atacados durante sus trayectos. Se trata por consiguiente de un espacio generalmente reservado para las prostitutas, Celestina y los

\footnotetext{
13 Más adelante, al verla en la calle, exclama Sempronio: "O yo no veo bien, o aquélla es Celestina. ¡Válala el diablo, haldear que trae!” (auto V, 138).

14 Nótese, sin embargo, que, como Celestina, Lozana siempre parece andar de forma apresurada: "Ves allí la Lozana que va de priesa" (mam. XXXIX, 200). No obstante, se trata más, en el caso de la protagonista de Delicado, de una estrategia para deshacerse de los clientes estorbosos, que de una mera prisa.
} 
criados. Éstos, que carecen de lugares propios, actúan en las calles como extensiones de sus amos, que rara vez salen de su casa. Ahora bien, además de su función como lugar de paso, en La Celestina la calle se vuelve lugar de artimañas: durante los paseos callejeros y Celestina trama sus maniobras, se sellan alianzas entre criados deseosos de engañar a sus amos. A modo de ejemplo, véase el principio de la primera conversación ambulante de Celestina:

Sempronio: $\quad$ Calisto arde en amores de Melibea; de ti y de mí tiene necesidad. Pues juntos nos ha menester, juntos nos aprovechemos, que conocer el tiempo y usar el hombre de la oportunidad hace los hombres prósperos.

Celestina: $\quad$ Bien has dicho; al cabo estoy; basta para mí mecer el ojo. Digo que me alegro destas nuevas como los cirujanos de los descalabrados; y como aquéllos dañan en los principios las llagas y encarecen el prometimiento de la salud, ansí entiendo yo hacer a Calisto. Alargarle he la certinidad del remedio, porque, como dicen, "el esperanza luenga aflige el corazón”, y cuanto él la perdiere, tanto gela promete (auto I, 51-52).

A la vez lugar de tránsito y de preparación del negocio, la calle de $L a$ Celestina se tiñe también con un matiz peyorativo: además de representar una fuente potencial de peligro, la calle se vuelve varias veces un espacio en el que los personajes expresan sus dudas y temores, como ilustra el famoso monólogo de Celestina del auto IV. ${ }^{15}$ Por su parte, Lozana se aprovecha al máximo de la calle como lugar de tránsito y de negocio. En los mamotretos LVII, LVIII y LIX, la alcahueta actúa por ejemplo de vendedora de cosméticos ambulante y sus constantes desplazamientos tienden a promover la competencia entre sus clientas y así a aumentar los precios. La alcahueta no suele expresar dudas y sus monólogos callejeros están siempre orientados hacia la acción. Sin embargo, este espacio también se matiza en La Lozana de forma algo negativa, puesto que la andaluza suele ser acosada en la calle por clientes impacientes y rameras rivales que le estorban el paso e incluso pueden llegar a insultarla. Si Delicado parece así retomar el papel ambiguo que Rojas atribuye a la calle, fuerza es constatar que, en el caso del Retrato, a la andaluza no la acechan circunstancias adversas sino más bien lo contrario: Lozana es ante todo víctima

15 Para un análisis de este soliloquio, véase Gerli (“'Agora que voy sola”). 
de su éxito, en estas calles "donde la llaman todos" (mam. XXVII, 141), como demuestra el siguiente fragmento:

\begin{tabular}{|c|c|}
\hline Portogués: & Señora, ¡si rapa la gracia de Deus, só vuestro! \\
\hline Lozana: & $\begin{array}{l}\text { ¿De eso comeseremos? Pagá si queréis, que no hay coño de } \\
\text { balde. }\end{array}$ \\
\hline Canavario: & $\begin{array}{l}\text { A quién digo... ¡señora Lozana!... ¡tan de priesa?... soy } \\
\text { forrier de aquélla ... }\end{array}$ \\
\hline Lozana: & $\begin{array}{l}\text { Para Vuestra Merced no hay priesa, sino vagar y como él } \\
\text { mandare. }\end{array}$ \\
\hline Guardarropa: & Me encomiendo, mi señora. \\
\hline $\begin{array}{l}\text { Lozana: } \\
{[\ldots]}\end{array}$ & Señor, sea Vuestra Merced de sus enemigos. \\
\hline Pierreto: & $\begin{array}{l}\text { Cabo de escuadra de Vuestra Merced, señora Lozana. } \\
\text { Adío, adío. }\end{array}$ \\
\hline Lozana: & A Dios va quien muere. \\
\hline Sobrestante: & Señora, una palabra. \\
\hline Lozana: & Diciendo y andando, que vo de priesa. \\
\hline Sobrestante: & $\begin{array}{l}\text { Señora, ¡cuerpo del mundo! ¿por qué no queréis hacer por } \\
\text { mí pues lo puedo yo pagar mejor que nadie. }\end{array}$ \\
\hline Lozana: & $\begin{array}{l}\text { Señor, ya lo sé, mas voy agora de priesa. Otro día habrá } \\
\text { (mam. XXVII, 141-142). }\end{array}$ \\
\hline
\end{tabular}

A pesar de las molestias que ocasionan este exceso de entusiasmo por parte de los clientes de Lozana, la calle representa ante todo un espacio de triunfo para la alcahueta a la que todos admiran y ven de lejos, como ilustra el diálogo entre un embajador y un caballero en el mamotreto XXXVI.

Otra discrepancia entre las alcahuetas rojana y delicadiana que de nuevo parece jugar a favor de Lozana radica en su complicidad con otros personajes. Los criados de La Celestina, y más concretamente Sempronio y Pármeno, se vuelven acólitos de la vieja barbuda porque esperan beneficios personales (ganancias pecuniarias o tratos carnales con Areúsa) de esta colaboración. A pesar de que Celestina les encargue algunos trayectos callejeros a modo de participación al negocio pendiente, los criados efectúan la mayor parte de sus desplazamientos por voluntad propia. A diferencia de su modelo, Lozana puede contar con un verdadero cómplice: no sólo Rampín, definido como "su marido, o criado pretérito, o amigo secreto, o esposo futuro" (mam. LVI, 279), le profesa una fidelidad absoluta, sino que funciona generalmente como extensión de Lozana que no deja de encomendarle recados. Rampín 
prolonga los movimientos callejeros de la andaluza: recoge sus ganancias (mam. XXXVII), compra los ingredientes de sus afeites (mam. XLVIII), cuenta sus andanzas al personaje del autor (XVII), y representa así, en suma, una ventaja nada despreciable que contribuye a acrecentar la fama y eficacia de los negocios lozanescos. ${ }^{16}$

\subsection{Umbrales}

Entre las casas y las calles, existen, evidentemente, fronteras. En La Celestina, las puertas y los muros impiden que los personajes se introduzcan en espacios reservados a otros personajes o por lo menos les imponen un plazo de espera, durante el cual los habitantes de la casa comentan estas llegadas antes de decidirse a facilitar la entrada de los visitantes. Estos períodos de latencia representan para los personajes ambulantes distintas ocasiones de perfeccionar sus engaños y trabajar su papel. Michel Moner ("Espacio dramático") habla a propósito de "scènes de seuil", o sea escenas de umbrales. El estudioso explica que este procedimiento es recurrente en La Celestina y permite la circulación de los personajes entre diferentes espacios sociales. Estas escenas, a menudo cómicas, sirven de entremeses a un cambio de lugar que es siempre problemático en el texto y necesita por tanto una adaptación previa de los personajes al lugar en el que quieren introducirse. Estas escenas sirven para demostrar la hipocresía de los personajes, ya que el lector puede observar una diferencia radical entre la actitud y la intención declarada del personaje antes y después de estas escenas de umbral. Es de notar que Bajtín considera justamente que el umbral representa un cronotopo estrechamente vinculado con el encuentro, pero también con la crisis y el cambio brusco, que el crítico ruso asocia con el sentido metafórico del umbral como lugar de pasaje (Moreno Hernández, "Diálogo, novela y retórica”, 23).

Ahora bien, fuerza es constatar que la función de esta ambigua frontera del umbral casi desaparece en La Lozana, aunque el franqueo de una puerta puede dar lugar a escenas cómicas, como en el caso del diálogo entre la alcahueta y una esclava negra cuya jerga es burlada (mam. XXIII). No obstante, por lo general el Retrato carece de escenas de umbrales: a diferencia de

16 Además, como indica Pancorbo Murillo ("La Lozana andaluza: nuevas hipótesis"): Rampín representa, a lo largo del Retrato, el personaje que "aporta mayor información en cuanto a la descripción del marco espacial en el que se desarrolla la novela, pues hace una exposición documental a lo largo de la primera parte en la que hace al lector saber en todo momento el espacio en el que se están desarrollando las acciones”.

Medievalia 48, 2016, pp. 107-129 
Celestina, Lozana no duda durante sus desplazamientos ni necesita escenas umbralísticas para prepararse, sino que entra directamente en casas ajenas donde ejecuta su plan.

\subsection{Dicotomía público-privado}

En la Tragicomedia, la tripartición espacial (casa, calle, umbral) testimonia también cierto carácter dicotómico, ya que, al espacio público, abierto y peligroso, se opone el espacio privado, cerrado y percibido como un refugio por parte de los personajes. No obstante, al hacerse mediadora entre tales espacios cerrados y abiertos, Celestina subvierte los sitios asignados y provoca el derrumbamiento de dicha estructura espacial. La protagonista rojana se vuelve agente de perturbación del espacio en primer lugar porque tiene que introducirse en casas ajenas para luego avivar las pasiones y así cumplir con su papel de tercera. Dicha intromisión en los espacios privados se intensifica a medida que se desarrollan los diálogos, ya que la alcahueta incluso llega a perseguir su trabajo de manipulación en la misma recámara de Calisto (auto VI). Asimismo, cuando Celestina desea asegurarse de la complicidad de Pármeno y le ofrece los servicios de Areúsa, la vieja asiste a sus retozos en la recámara de la ramera e incluso anima al joven: "llégate acá, negligente, vergonzoso, que quiero ver para cuánto eres antes que me vaya” (auto VII, 181). Al entrometerse poco a poco en la intimidad de los personajes, la tercera transforma así la categoría de lo privado en una categoría inoperante.

Además, el mismo espacio de lo privado se fragmenta con estas intromisiones celestinescas. Cuando la alcahueta entra en casa de Calisto durante el primer acto, se asegura de que Calisto se aleje en la primera planta con el fin de quedarse a solas con Pármeno y ganar su confianza. Durante este proceso, Celestina aviva en la mente del criado sentimientos negativos hacia Calisto. La tercera empieza a corromper de este modo el vínculo de fidelidad entre el criado y su amo. La división de la casa en distintos lugares de acción simultáneos representa así un procedimiento recurrente en la obra de Rojas, en la que la pérdida de cohesión espacial engendra la pérdida de cohesión social.

Ahora bien, huelga decir que tales intromisiones de Celestina en casas ajenas representan invasiones puntuales. Por su parte, Lozana hace alarde de estrategias a largo plazo. En efecto, la alcahueta andaluza suele comportarse conscientemente como un parásito que no sólo se introduce en las casas de los demás, sino que se apodera de éstas y allí se instala. Imperiale ha señalado la "atracción que ejerce sobre ella la vida del parásito" ("Itinerario peripatético”, 104-105). Ilustra esta atracción, hecha filosofía vital, la pregunta que 
Lozana le hace a Rampín: "¿Quién mejor sabio que quien sabe sacar dinero de bolsa ajena sin fatiga?” (mam. XV, 72). Más adelante, la discusión que Lozana entabla con Trigo afianza esta voluntad parasitaria:

Trigo: Señora, yo os he hallado una casa de una señora rica que es estada cortesana, y agora no tiene sino dos señores que la tienen a su posta, y es servida de esclavas como una reina, que está parida y busca una compañía que le gobierne su casa.

Lozana: $\quad$ ¿Y dónde mora?

Trigo: $\quad$ Allá, detrás de Bancos. Si is allá esta tarde, mirá que es una casa nueva pintada y dos gelosías y tres encerados.

Lozana: Sí haré, por conocer y experimentar, y también por comer a espesas de otrie (XXII, 110-113, cursivas mías).

Al llegar a esta casa, Lozana expone directamente un remedio para el dolor de madre del que padece la cortesana. Ésta invita enseguida a que la andaluza tome el control de su hogar: "Señora, vos no os habéis de partir de aquí, y quiero que todos os obedezcan, y miréis por mi casa y seáis señora de ella, y a mi tala y a mi bien y a mi mal, quiero que os halléis" (mam. XXIII, 116). Bien es cierto lo que afirmará más tarde un caballero: "sus injertos [de Lozana] siempre toman" (mam. XXXVI, 186). Además, es interesante señalar que, a través de estas intromisiones, Lozana suele desempeñar el papel de los médicos, a los que resta autoridad, tachándoles de incompetentes, y que suele echar de las casas para tomar su lugar, como lo ejemplifican las quejas de los médicos de los mamotretos LIX y LXI. Lozana combina, pues, la conducta del parásito con la del cuco.

\section{El ESPACIO DEL LIBRo}

Para terminar este examen de los espacios de La Lozana y La Celestina, es de interés destacar una última peculiaridad del texto delicadiano con respecto a su modelo rojano. En efecto, otro espacio en el que Lozana se mueve de forma consciente, a diferencia de su modelo, es el espacio del propio Retrato. Sobresalen efectivamente en el texto de Delicado ciertos procedimientos metaficcionales, que parecen anticipar los del Quijote: en varios puntos del relato el escritor se incorpora en su ficción como un personaje llamado "autor" a quien vemos recoger datos sobre Lozana y, sobre todo, escribir este mismo texto que estamos leyendo. La andaluza sabe muy bien que los espacios que 
ella recorre al hilo de sus diálogos se retoman en el espacio de la escritura. Lozana incluso coquetea con su autor, que es uno de sus clientes, y alaba su Retrato: "Quiérolo [el autor] yo muncho, porque me contrahace tan natural mis meneos y autos" (mam. XLVI, 229). La alcahueta de Delicado destaca así por ser un personaje altamente consciente de su entorno y de las posibilidades de los múltiples espacios, tanto ficticios como reales, que atraviesa.

\section{CONCLUSiones}

De este estudio comparativo del tratamiento espacial en los textos de Rojas y Delicado, se desprenden a la vez diferencias y similitudes, o, mejor dicho, 126 disparidades dentro de las semejanzas. En efecto, ambos textos comparten una misma configuración espacial urbana, dividida en calles y casas, en la que las protagonistas derrumban la frontera entre los ámbitos de lo privado y de lo público. Pero el Retrato caracteriza a Lozana como un personaje aún más móvil que su antecesora: cambia de países, se muda de casa $\ldots{ }^{17}$ La filosofía de la deambulación de la que hace alarde permite que Lozana se aproveche al máximo de los espacios y que no tenga que aguantar sus peligros, a diferencia de Celestina. La gestión del espacio de la andaluza demuestra una alta conciencia profesional: tanto su instalación en Roma como su repartición de los clientes a nivel espacial representan unas de las estrategias que utiliza para conseguir su autonomía y acrecentar sus ganancias.

Todas estas características y matices que Delicado añade al modelo rojano permiten así hacer de Lozana un personaje dueño de su destino. Los distintos finales que conocen Celestina y Lozana bien pueden interpretarse a la luz de estos diferentes niveles de conciencia y, por tanto, dominio del entorno. Celestina muere acuchillada en su propia casa, es decir, en su propio espacio, por no haber calculado los riesgos que implicaba su confederación con los criados (Snow, "Confederación e ironía"). A cambio, el exilio final de Lozana es voluntario: se va a vivir a la isla de Lípari después de un sueño premonitorio que le anuncia el saqueo de Roma (mam. LXVI). Los editores Joset y Gernert (Delicado, La Lozana, 318) señalan los juegos de palabras a base de pari, pares a los que da lugar el nombre de la isla "Parece ser, pues, el lugar ideal de reunión de pares que pueden ser a la vez cortesanas romanas que decidieron retraerse como Lozana y los amigos-amantes-maridos de las mismas,

17 Es de notar que algunos críticos interpretan esta movilidad hiperbólica del personaje como una metáfora del constante exilio sefardí. Véase García Verdugo (“Geografía del exilio”). 
como Rampín” (Delicado, La Lozana, 325, n. 27). Sin embargo, en uno de los textos que agregó Delicado al final del Retrato, el autor indica que "cuando un hombre hacía un insigne delito, no le daban la muerte, mas condenábanlo a la ínsula de Lípari” (331). Los editores observan a este respecto que:

el hecho de que Lípari fuese lugar de exilio para insignes delincuentes (retraimiento), por lo menos en la geografía imaginaria de Delicado, echa una sombra sobre el retiro o retraimiento de Lozana: la paz buscada ahí es paz forzada así como el arrepentimiento y conversión (Delicado, La Lozana, 331, n. 8).

A pesar de este matiz peritextual, lo cierto es que el Retrato insiste en que Lozana decide de su exilio, sea salvación o condena, por su iniciativa personal. No sólo Lozana es capaz de adaptarse a las distintas circunstancias espaciales — como indica de forma sintomática el cambio de identidad onomástica que acompaña sus cambios de espacio más destacados — ${ }^{18}$ sino que también es capaz de prever a tiempo las circunstancias adversas, o sea el Saco de Roma, y puede huir a tiempo de un espacio inseguro, al contrario de Celestina. En esta dinámica general, el tratamiento espacial representa así otro nivel en el que Lozana compite con su famosa antecesora.

\section{BIBLIOGRAFÍA}

Blay Manzanera, Vicenta y Dorothy Severin, Animals in "Celestina”, London: Queen Mary and Westfield College, 1999.

Botta, Patrizia, "Itinerarios urbanos en La Celestina de Fernando de Rojas", Celestinesca, 18: 2, 1994, 113-131.

Botta, Patrizia, “Onomástica lozanesca (Topónimos, 3)”, en Manuel Criado de Val (ed.), Caminería Hispánica. Actas del VI Congreso Internacional (Italia-España), Madrid: Ministerio de Fomento-Cedex, 2004, 887-904.

Bubnova, Tatiana, "Delicado en la Peña de Martos", Actas XII de la Asociación Internacional de Hispanistas, Birmingham: University of Birmingham, 1998, 70-78.

Costa Fontes, Manuel, “The Art of 'Sailing' in La Lozana andaluza”, Hispanic Review, IV, 1998, 433-445.

Delicado, Francisco, La Lozana andaluza, ed., estudio y notas de Folke Gernert y Jacques Joset, Barcelona: Galaxia Gutenberg-Círculo de Lectores, 2013.

18 La andaluza "gozó de tres nombres: en España, Aldonza, y en Roma, la Lozana, y en Lípari, la Vellida” (328).

Medievalia 48, 2016, pp. 107-129 
Deyermond, Alan, "Hilado-cordón-cadena: Symbolic Equivalence in La Celestina”, Celestinesca, I, 1977, 6-12.

García Verdugo, Marisa, "Geografía del exilio sefardí en La Lozana andaluza", Tejuelo, 6, 2009, 7-15.

Gerli, E. Michael, “'Agora que voy sola': Celestina, Magic and the Disenchanted World”, eHumanista, 19, 2011, 157-171.

Gilman, Stephen, La Celestina: arte y estructura, Madrid: Taurus, 1982.

Hernández Ortiz, José A., La génesis artística de La Lozana andaluza. El realismo literario de Francisco Delicado, Madrid: Ricardo Aguilera, 1974.

IMPERIALE, LOUIS, "Itinerario peripatético y evolución interior en La Lozana andaluza”, Castilla: Estudios de literatura, XVIII, 1993, 99-108.

Joset, JACQUes, “.... y contiene munchas más cosas que la Celestina”, Cultura Neolatina, LVII, 1997, 147-166.

Joset, Jacques, “Preliminar: el otro humanismo de Francisco Delicado”, en Francisco Delicado, La Lozana andaluza, ed., estudio y notas de Folke Gernert y Jacques Joset, Barcelona: Galaxia Gutenberg-Círculo de Lectores, 2013, 353-370.

Lida de Malkiel, María Rosa, Two Spanish Masterpieces: "The Book of Good Love" and "The Celestina", Urbana: The University of Illinois Press, 1961.

Maravall, José Antonio, "Afán de lucro y economía dineraria. El mundo celestinesco como producto de la cultura urbana”, en El mundo social de La Celestina, Madrid: Gredos, 1986.

Moner, Michel, "Espacio dramático y espacio simbólico en La Celestina de Fernando de Rojas”, en Ignacio Arellano, María del Carmen Pinillos, F. Serralta y Marc Vitse (eds.), Studia Aurea. Actas del III Congreso de la AISO (Universidad Toulouse Le Mirail 1993), Pamplona: GRISO, 1996, 279-290.

Montserrat Villagrá Terán, María, La Lozana andaluza en el siglo de los humanistas: Un "retrato" que parodia otro retrato, tesis, Madrid: Universidad Nacional de Educación a Distancia, 2013.

Moreno Hernández, Carlos, “Diálogo, novela y retórica en Celestina”, Celestinesca, 18:2, 1994, 3-30.

Olalla Real, Ángela, "Tú no has venido a Roma para soñar. Algunas notas sobre La Lozana andaluza”, en Nicolás Marín, Antonio Gallego Moreli y Andrés Soria Ortega (coords.), Estudios sobre literatura y arte dedicados al profesor Emilio Orozco Díaz, II, Granada: Universidad de Granada, 1979, 559-579.

Pancorbo Murillo, Fernando José, “La Lozana andaluza: nuevas hipótesis sobre su estructura y la codificación del marco espacio-temporal”, en línea: https:// www.academia. edu/4818285/La_Lozana_Andaluza_Nuevas_hipótesis_sobre_ su_estructura_y_la_codificación_del_marco_espacio-temporal

Rojas, Fernando de, La Celestina. Tragicomedia de Calisto y Melibea, ed. y estudio 
de F. J. Lobera, G. Serés, P. Díaz-Mas, C. Mota, I. Ruiz Arzalluz y F. Rico, Barcelona: Galaxia Gutenberg-Círculo de Lectores, 2011.

Salvador Miguel, Nicasio, "Huellas de La Celestina en La Lozana andaluza", Estudios sobre el Siglo de Oro. Homenaje al profesor Francisco Ynduráin, Madrid: Editora Nacional, 1984, 431-459.

SnOw, Joseph T., "Confederación e ironía: crónica de una muerte anunciada (Celestina, autos I-XII)”, Celestinesca, 37, 2013, 119-138.

WARdropper, Bruce W., "La novela como retrato: el arte de Francisco Delicado", Nueva Revista de Filología Hispánica, VII, 1953, 475-488.

Weinberg, F. M., "Aspects of symbolism in La Celestina", Modern Languages Notes, 86, 1971, 136-153. 